\title{
High IFN-gamma and TNF production by peripheral NK cells of Colombian patients with different clinical presentation of Plasmodium falciparum
}

Olga Agudelo1, Julio Bueno², Andres Villa ${ }^{3}$ and Amanda Maestre ${ }^{1 *}$

\begin{abstract}
Background: In Colombia, Plasmodium falciparum infection rarely results in severe disease or mortality compared to infections in African populations. During natural infection NK cells exhibit a cytolytic effect and regulate dendritic cells, macrophages, neutrophils as well as affect antigen specific T and B cell responses. To characterize the NK cells in P. falciparum infected patients of a highly endemic region of Colombia, the degree of NK proliferation and production of IFN gamma and TNF production in these cells were explored.

Methods: Seventeen patients with acute and three with severe $P$. falciparum malaria patients from the Northwest region of the country were recruited in the study. In addition, 20 healthy controls were included: 10 from Medellin (no-transmission area) and 10 from the Uraba region (a malaria endemic area). Immunophenotypic analysis of peripheral mononuclear cells was performed by FACS to detect total number of NK cells, subtypes and intracellular IFN $\gamma$ and TNF production by NK cells in the different patient groups.

Results: The total mean $\mathrm{CD}^{+} 6^{+} / \mathrm{CD}^{-}{ }^{-} \mathrm{NK}$ cell proportions in acute and severe malaria subjects were $9.14 \%$ (7.15\% CD56 $\left.{ }^{\mathrm{dim}}, 2.01 \% \mathrm{CD}^{\mathrm{b}} 6^{\text {bright }}\right)$ and $19.62 \%\left(16.05 \% \mathrm{CD}^{\mathrm{dim}}, 3.58 \% \mathrm{CD}^{\mathrm{d}} 6^{\text {bright }}\right)$, respectively, in contrast to healthy controls from endemic (total mean $\mathrm{CD}^{+} 6^{+} / \mathrm{CD}^{-1} 1.2 \%$ ) and non-endemic area (total mean $\mathrm{CD}^{2} 6^{+} / \mathrm{CD}^{-}$0.67\%). Analysis of basal IFN $\gamma$ and TNF levels confirmed the CD56 bright $N K$ population as the main cytokine producer $(p<$ 0.0001) in the groups affected with malaria, with the CD56 ${ }^{\text {dim }}$ NK cell exhibiting the highest potential of TNF production after stimulus in the acute malaria group.

Conclusions: The results confirm the important role of not only CD56 bright but also of CD56 ${ }^{\text {dim }}$ NK cell populations as producers of the two cytokines in malaria patients in Colombia.
\end{abstract}

\section{Background}

The clinical presentation of malaria depends on the confluence of diverse factors, including the degree of natural and acquired specific immunity, host's genetic composition, age, occupation and social and economic factors of the population [1].

Malaria in Colombia is highly endemic in the northwest, Pacific Coast and Amazon regions, all among the most deprived of the country due to social-political

\footnotetext{
* Correspondence: aemaestre@gmail.com

${ }^{1}$ Grupo Salud y Comunidad, Facultad de Medicina, Universidad de Antioquia, Medellin, Colombia
}

Full list of author information is available at the end of the article conflicts resulting in migrations and poverty. Previous studies in the northwest of Colombia, confirmed that children below 12 years of age are highly susceptible to malaria with a mean seven years of age for clinical presentation with malaria [2]. About $70 \%$ of this young population was affected by chronic malnutrition and $85 \%$ with intestinal parasitism, two conditions with important effects on the immune fitness of malaria affected individuals $[2,3]$.

Despite the high frequency of Plasmodium falciparum infection, severe or fatal malaria cases are rare in the country. Out of the 79,909 malaria cases (72\% Plasmodium vivax-27\% P. falciparum) reported in 2009, 307 
were severe (1.4\% of P. falciparum cases) and the fatality rate was $0.04 \%$ [4]. This is in striking contrast to reports from African populations, where around $0.4 \%$ mortality rates were reported in the same year, most of them in children under 5 years of age [5]. In Colombia, is the 20-24 age group the most frequently affected by malaria, with around $15 \%$ of total cases, followed by the 15-19 age group (around 14\%) and the 10-14 age group (around 12\%). For severe malaria, the most commonly affected groups is the 20-24 age group (around 21\%) and the 15-19 age group (around 13\%)[6]. This is evidence of a clear-cut difference in the age pattern of severe malaria presentation between Colombia and African countries.

For many years, the importance of effective acquired immune response to protect against severe $P$. falciparum infection has been known. In this sense, both innate and adaptative immune responses, constitute a key component in subsequent Plasmodium challenges by reducing parasitaemia during the acute phase of the disease [7]. After infection with a microorganism, natural killer (NK) cells lymphocyte lineage cells exhibit a cytolytic effect, which, can directly induce the death of infected cells in absence of specific immunization. Subsequently, NK cells have been recognized as major producers of interferon- $\gamma($ IFN- $\gamma$ ) and other cytokines, either pro-inflammatory or anti-inflammatory, including tumor necrosis factor (TNF), interleukin (IL)-10, and growth factors such as GM-CSF (granulocyte macrophage colony-stimulating factor), G-CSF (granulocyte colony stimulating factor), and IL-3. NK cells also secrete many chemokines, including CCL2 (MCP-1), CCL3 (MIP1- $\alpha)$, CCL4 (MIP1- $\beta$ ), CCL5 (RANTES), XCL1 (lymphotactin), and CXCL8 (IL-8) [8].

The evidence gathered so far confirms that NK cells can positively $[9,10]$ or negatively $[11]$ influence the host's $\mathrm{T}$ and $\mathrm{B}$ cell immunity, depending on the nature of the antigenic challenge. Therefore, in addition to their cytolytic effect, NK cells can also regulate dendritic cells, macrophages, neutrophils [12] and affect antigen specific $\mathrm{T}$ and $\mathrm{B}$ cell responses [13]. According to the expression density of CD56, NK cells can be divided into $\mathrm{CD} 56^{\mathrm{dim}}$ representing the vast majority of human NK cells and a small distinct population of CD56 $6^{\text {bright }}$ NK cells $[14,15]$. Almost all CD56 $6^{\text {bright }}$ NK cells fail to express CD16 and exhibit a weak cytotoxic activity. In healthy humans, CD56 ${ }^{\text {bright }}$ cells comprise up to $10 \%$ of all NK cells. Granules of CD56 ${ }^{\mathrm{dim}}$ cells are richer in perforin and granzyme A, which results in a more effective cytolysis compared to CD56 ${ }^{\text {bright }}$ NK cells. However, CD56 ${ }^{\text {bright }} \mathrm{NK}$ cells are more efficient in producing the pro-inflammatory cytokines IFN $\gamma$ and TNF [16].

The presence of severe malaria has been strongly attributed to an exaggerated immune response of the host towards parasite antigens and several authors reported on the positive correlation between high TNF production and cerebral malaria in humans as well as in animal models [17]. Parasite genetic diversity does not seem to influence TNF-mediated effects on the virulence of primary rodent malaria infections [18]. Recent studies on naïve volunteers confirmed the contribution of NK cells to total IFN $\gamma$ production and the existence of memory responses to parasitized erythrocytes [19].

Based on the limited and controversial knowledge on the function of NK cells during the inflammatory process leading to severe malaria and the important role of TNF and IFN $\gamma$ in the pathogenesis of the complicated disease, the study proposed to correlate the production of pro-inflammatory cytokines by these cells and their subsets, and the clinical outcome in malaria patients in Colombia. The characteristics of NK cells in P. falciparum-infected patients of a highly endemic region of Colombia are described. In addition, the degree of NK proliferation and production of IFN $\gamma$ and TNF production by these cells was explored, with the aim of providing a first glimpse into their profile in naturally-infected populations on this continent.

\section{Methods}

\section{Subject enrolment}

The study took place in Medellin-Colombia, where patients from the northwest region of the country attended the malaria clinic of Grupo Salud y Comunidad, Universidad de Antioquia. A total of 23 acute (non-severe) and seven severe P. falciparum malaria patients were recruited. Individuals were included immediately after diagnosis of $P$. falciparum infection was performed by microscopy. Inclusion criteria for this group were: permanent residency in the endemic area, presence of symptomatic malaria and absence of clinical viral infections within 2 months of attendance to the malaria clinic. The degree of clinical impairment was assessed by an experienced medical officer. Patients were classified as having acute malaria or severe malaria according to the WHO criteria[20]. Concomitant infection with other agents was excluded by clinical evaluation and completion of a questionnaire. In addition, 20 healthy controls were included: 10 from Medellin (nontransmission area) and 15 from the Uraba region (malaria-endemic area). Controls were recruited after exclusion of acute disease or infection by physical examination and completion of a questionnaire, which was also used to out rule previous history of malaria. Inclusion criteria for this group were permanent residency in Medellin or the endemic area, absence of symptomatic malaria and any clinically apparent viral infection within 2 months of inclusion. Companions attending the malaria clinics in endemic and non-endemic areas were 
recruited as controls in a sequential manner for the study.

Volunteers were notified of the risks and their rights and enrolled after providing informed consent. Ethical clearance was granted by the Ethics Committee of the Centro de Investigaciones Medicas, Faculty of Medicine, Universidad de Antioquia (Medellin-Colombia).

\section{Microscopy for Plasmodium detection}

Giemsa-Field stained thick/thin blood films were examined with a $100 \times$ objective to identify presence of parasites, Plasmodium species, parasite density, and schizontaemia. Parasite density was measured by counting the number of asexual parasites per 200 leukocytes, based on a mean count of 8,000 leukocytes per microlitre of blood (theoretical value). A slide was considered negative after examination of at least 300 microscopic fields [21].

\section{Isolation of peripheral mononuclear cells}

Blood samples from volunteers were obtained from peripheral vein and, in the case of malaria subjects, before malaria treatment was administered. Samples of $16 \mathrm{~mL}$ were collected into EDTA vacutainer vials from patients and controls and peripheral blood mononuclear cells were separated by density centrifugation (Ficoll-Hypaque 1077). Mononuclear cells were collected from the interface, washed twice by centrifugation with EDTA-PBS at $640 \mathrm{~g}$ and $160 \mathrm{~g}$, respectively, for $10 \mathrm{~min}$ at $4^{\circ} \mathrm{C}$. Cells were then suspended in complete RPMI 1640 medium buffered with $25 \mathrm{mM}$ Hepes and supplemented with 12 $\mathrm{mM}$ sodium bicarbonate, $2 \mathrm{mM}$ L-glutamine, $100 \mathrm{U} / \mathrm{mL}$ penicillin, $100 \mathrm{mg} / \mathrm{mL}$ streptomycin and $5 \%$ foetal bovine serum. Cell viability was assessed with $0.1 \%$ trypan blue in PBS pH 7.3.

\section{Flow cytometry}

Immunophenotypic analysis of cells was performed using four-colour analysis on a FACSCalibur (Becton Dickinson, San Jose, CA) with CELLQuest Pro software (Becton Dickinson). Cells were stained with the following monoclonal antibodies: fluorescein isothiocyanate (FITC)-conjugated anti-CD56 (SIGMA) and Cychrome (Cy)-anti-CD3 (SIGMA) to determine the percentage of NK cells within the sample. Gating was performed according to size and granulation using forward-scatter versus side-scatter (FSC/SSC) dot plots.

Production of INF $\gamma$ and TNF by NK cells was determined by flow cytometry. For this, $10^{6}$ freshly isolated mononuclear cells per well were incubated with phorbol myristate acetate (PMA) $10 \mathrm{mg} / \mathrm{ml}$ plus calcium ionophore $250 \mathrm{ng}$ and brefeldin A $0.4 \mathrm{mg} / \mathrm{mL}$ for $6 \mathrm{~h}$ at $37^{\circ}$ $\mathrm{C}$ in $5 \% \mathrm{CO}_{2}$. Analysis included a description of the total NK cell and subtypes populations according to
IFN $\gamma$ and TNF production in the different groups of study: acute malaria, severe malaria, and healthy volunteers from endemic and non-endemic area. Results were processed using Prisma ${ }^{\circledR}$, and mean values and standard deviations were compared using t-student.

\section{Results}

Natural killer population analysis in the malaria affected group was successfully performed in 17 acute malaria and three severe malaria volunteers. Samples from 10 subjects from Medellin (non-endemic) and 10 from Uraba (endemic region) were processed as controls.

The male/female ratio in the experimental group was $16 / 4$ and the age ranged from 18 to 59 years old (mean 34 \pm 14 ). The male/female ratio in the controls was $13 / 7$ and the age ranged from 18 to 49 years old (mean $33.3 \pm 9.9$ ). Among the patients with acute malaria, the most common symptoms were fever (100\%), chills (88\%) and sweating (47\%), while other complaints such as diarrhoea and vomiting were rare. Parasitaemia in these patients ranged between 80 and 9,440 rings $/ \mathrm{mm}^{3}$ (mean 5,640 $\pm 2,281$ ). All patients with severe malaria reported fever, chills, sweating, general malaise, headache, vomiting, two reported dizziness and one had abdominal pain. Parasitaemia in each of these patients was 154,000, 171,000 and 195,000 rings $/ \mathrm{mm}^{3}$ (mean 173,500 rings $/ \mathrm{mm}^{3}$ ). The diagnosis of severe malaria was based on the high number of vomiting episodes per day and hyperparasitaemia.

\section{NK cell population distribution}

In acute malaria-infected patients, the total $\mathrm{CD}^{2} 6^{+} / \mathrm{CD}^{-}$ NK cell population was $9.1 \pm 0.3 \%$ of which $7.1 \pm 0.4 \%$ were CD56 ${ }^{\mathrm{dim}}$ and $2.0 \pm 0.2 \%$ were CD56 $6^{\text {bright }}$. Meanwhile, in patients with severe malaria, the total population of $\mathrm{CD} 6^{+} / \mathrm{CD}^{-}$was $19.6 \pm 0.6 \%$ and the mean CD56 ${ }^{\mathrm{dim}}$ and CD56 $6^{\text {bright }}$ populations were $16.0 \pm 0.3 \%$ and $3.6 \pm 0.9 \%$, respectively. These proportions of NK cells in acute malaria-infected and severe patients were statistically similar. After PMA and calcium ionophore addition, cells from complicated malaria patients showed higher levels of both CD56 ${ }^{\text {dim }}$ and CD56 $6^{\text {bright }}$ populations when compared to acute malaria patients (see Figure 1).

The mean $\mathrm{CD} 6^{+} / \mathrm{CD}^{-}$population in healthy volunteers from a malaria endemic area was $1.2 \pm 0.6 \%$ and in healthy volunteers from the non-endemic area the mean was $0.7 \pm 0.2 \%$. The low numbers of NK cells in these two control groups, made discrimination between CD56 ${ }^{\mathrm{dim}}$ and CD56 ${ }^{\text {bright }}$ populations not feasible due to particular ethical constraints of the project to obtain the large volume of blood required to perform such analysis.

\section{Intracellular IFN $\gamma$ production}

NK cells were responsible for $2.4 \%$ of the total IFN $\gamma$ production in subjects with acute malaria, and this 


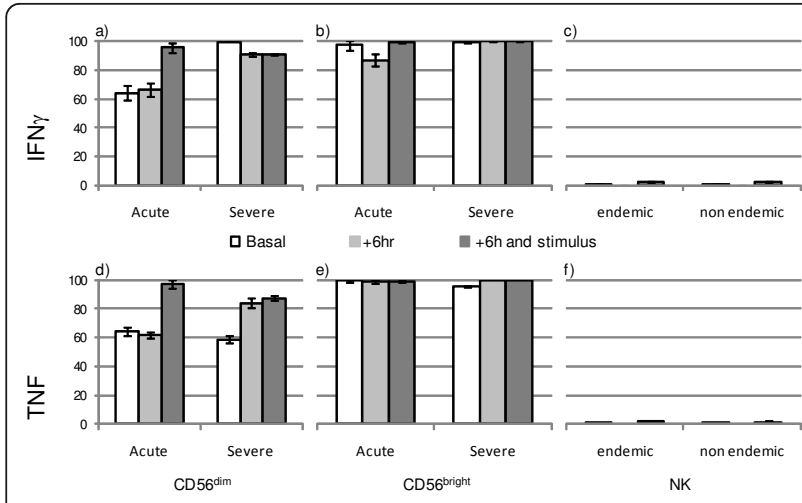

Figure 1 Proportions of cytokine producing natural killer cells according to clinical status. Acute malaria vs. severe malaria subjects under basal conditions, $6 \mathrm{~h}$ after culture $(+6 \mathrm{hr})$ and $6 \mathrm{~h}$ after culture plus stimulation with PMA, calcium ionophore Brefeldin A ( $+6 \mathrm{hr}$ and stimulus). The proportions of IFNy producing CD56 dim (a) and CD56 bright (b) cells, proportions of TNF producing CD56 ${ }^{\text {dim }}$ (d) and CD56 bright (e) cells. IFN $(\mathbf{c}$ ) and TNF (f) production by total NK cell population were assessed in healthy controls from endemic and non-endemic regions.

proportion was significantly lower compared to the $6.64 \%$ observed in severe malaria patients. A mean 76.7 $\pm 2.3 \%$ of NK cells from acute malaria patients produced IFN $\gamma$. In patients with severe malaria, $94.6 \pm 2.4 \%$ of NK cells were IFN $\gamma$ producers. After stimulus, the proportion of IFN $\gamma$-producing NK cells increased to $96.4 \pm$ $3.5 \%$ in acute malaria patients and to $99.0 \pm 3.6 \%$ in severe malaria patients. In controls from endemic and non-endemic areas, baseline proportion of IFN $\gamma$ producing cells was $0.2 \pm 1.1 \%$ and increased to $2.5 \pm 0.3 \%$ after stimulus, in all cases significantly lower than infected subjects. Representative dot plots of these results are presented in Figure 2.

Analysis of basal IFN $\gamma$ production according to the CD56 ${ }^{\text {dim }}$ or CD56 $6^{\text {bright }}$ phenotype confirmed that in both acute malaria and in severe malaria subjects, the CD56NK ${ }^{\text {bright }}$ population produced significantly higher levels of cytokine $(p<0.0001)$ than the CD56 ${ }^{\mathrm{dim}}$ population (Figure 1a-b). On the other hand, after 6 hours of stimulus with calcium ionophore, CD56 ${ }^{\mathrm{dim}}$ cells from malaria-infected patients produced the highest levels of IFN $\gamma$ regardless of their clinical presentation.

\section{Intracellular TNF production}

The proportion of NK cells producing TNF in acute malaria subjects under basal conditions was $70.3 \pm 2.1 \%$. This proportion was significantly lower compared to the $92.5 \pm 2.6 \%$ observed in severe malaria subjects. The proportion of TNF-producing NK cells rose to > 97\% after stimulus in the two groups. Controls from endemic and non-endemic areas exhibited a significant $<0.3 \%$ of TNF producing cells, in comparison with infected
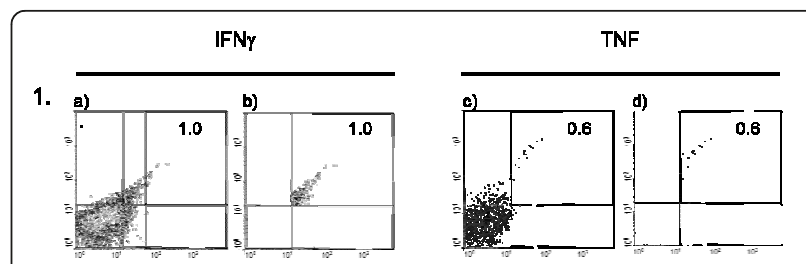

2.
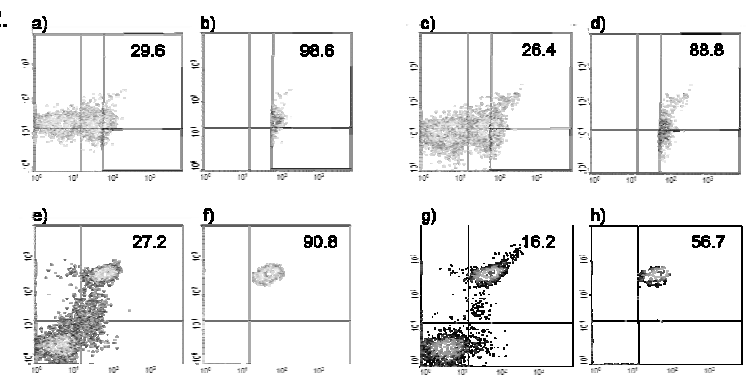

Figure 2 Representative dot plots demonstrating the method of gating of CD56 cell and subsets and the production of cytokines according to clinical status. A comparison of nonstimulated total CD56 cells collected from a typical uninfected control (Panels 1 a-d) and CD56 ${ }^{\text {dim }}-C_{\text {C } 56^{\text {bright }}}$ cells from a malaria infected subject (Panels $2 \mathbf{a}-\mathbf{h}$ ), is presented. Numbers in the quadrant represent percent of cytokine cell producing cells (1a, 1c, $2 \mathrm{a}, 2 \mathrm{c}, 2 \mathrm{e}, 2 \mathrm{~g}$ ) and proportion of the cytokine produced by a particular cell subset (1b, 1d, 2b, 2d, 2f, 2h).

subjects, either before or after stimulus. Analysis of basal TNF production according to the CD56 ${ }^{\mathrm{dim}}$ or CD56 $6^{\text {bright }}$ phenotype confirmed that in acute malaria subjects, as well as in severe malaria, the CD56 $6^{\text {bright }}$ population produced significantly higher levels of the cytokine $(p<0.0001)$ than the CD56 ${ }^{\mathrm{dim}}$ population (Figure $1 \mathrm{~d}$-e). However, after 6 hours of stimulus with calcium ionophore, CD56 ${ }^{\mathrm{dim}}$ cells from acute malaria and from severe malaria subjects produced significantly higher levels of TNF (Figure 1f).

\section{Discussion}

Early events of the immune response against pathogens involve the activation of the innate arm of immunity, which then regulates the subsequent adaptative immune response required to control infection [22]. For many years, NK cells have been proposed to play a significant role in clearance of protozoan parasites [23,24] including blood-stage malaria parasites [25], due to their early activation after infection. Upon contact with infected cells, NK cells proliferate and release cytokines by a complex system of triggering and inhibitory molecules $[26,27]$. They recognize major histocompatibility complex (MHC) class I molecules via membrane receptors that deliver inhibitory signals of NK-cell cytotoxicity. If target cells lack or express insufficient density of MHC class I molecules, as occurs during infection, cytotoxicity takes place. NK cell-mediated cytotoxicity occurs mainly 
after binding of NK cells to target cells and release of preformed granules containing perforin and granzymes in the intercellular space, leading to the lysis of target cells within minutes [28].

NK cells are among the first lymphocytes to respond to $P$. falciparum-infected red cells by producing IFN $\gamma$ as evidenced by in vitro [29,30] and in vivo studies [31]. Moreover, exposure of naïve volunteers to a single malaria $P$. falciparum infection was able to induce robust and lasting cellular responses of both $\mathrm{T}$ and NK cells [19]. Studies on the dynamics of NK activity in malaria patients revealed heterogeneous results, particularly in P. falciparum infected individuals. Nevertheless, confirmation of NK activation has been observed in subjects with Plasmodium vivax or P. falciparum infection [32].

This study detected increased NK cell population in all infected subjects, with similar proportions both CD56 ${ }^{\mathrm{dim}}$ and $\mathrm{CD} 56^{\text {bright }}$ populations, and, albeit the low number of individuals, this seemed marked in severe malaria cases. Other authors have demonstrated a similar pattern of NK increase in both CD $56^{\mathrm{dim}}$ and CD56 ${ }^{\text {bright }}$ after controlled challenge with $P$. falciparum, reporting an increase of around $12 \%$ in NK cells during acute infection [19]. Kassa et al. [33] reported normal NK cell counts in $P$. falciparum or $P$. vivax malaria. However, other researchers have reported lower counts of NK cells, and other lymphocytes, in a Plasmodium berghei murine model [34] and during acute P. falciparum malaria [35-37]. These conflicting results might be due to differences in the baseline values of the absolute counts of the immune cells of the subjects of study. Alternatively, an impact of different geographical locations which has been suggested by other authors, might account for such diverse results [34].

The increased of the NK population proportions during acute and, probably, during severe malaria described in this study, in addition to a positive correlation between NK cytotoxicity and levels of parasitaemia reported by other authors in patients infected with $P$. falciparum [32], confirms the induction of robust cellular responses to $P$. falciparum in naturally infected individuals form the American continent, and highlights the importance of further exploring the role of these cells and theirs subsets in the immunopathology during severe malaria outside Africa.

Activated cells belonging to the two arms of immunity (innate and adaptative) can produce IFN- $\gamma$. In malaria, the main cellular sources of the cytokine are T cells, $\gamma \delta$ $\mathrm{T}$ cells, and NK cells. However, in some subjects, there is little or no evidence of an NK cell response after exposure to $P$. falciparum-infected erythrocytes, whereas in other individuals, NK cells comprise around $70 \%$ of IFN $\gamma$-producing cells $[29,38]$. Controversial findings were recently reported on naïve subjects infected with $P$. falciparum, in whom NK cells represented, on average, $14 \%$ of IFN $\gamma$-producing cells before challenge, rising to $17 \%$ immediately after inoculum and by week 20 postinfection, represented only $7 \%$, when $\mathrm{T}$ cells reached a peak of production of the cytokine [19]. Such proportions of IFN $\gamma$-producing cells are very high compared to the results presented here in all groups of subjects regardless of the presence of infection: $2.43 \%$ in acute and $6.64 \%$ in severe malaria $v s .0 .22 \%$ in controls, and might reflect the heterogeneity of innate immune responses between donors, and/or populations [30,38] with crucial influencing factors such as type of nutrition [39], among other. Although the effects of the age on these results is possible, the authors consider this unlikely since the groups were homogenous in age and the severe malaria subjects also belonged to the most frequently malaria affected age range in the country. Existence of non-homogenous immune responses is supported by evidence of different strength co-stimulatory signals from myeloid accessory cells and polymorphism among NK regulatory receptors $[40,41]$. In addition, many reports confirm the requirement of IL-2 as a contributor of IFN $\gamma$ production by NK cells $[19,42]$. However, recent reports on pregnant mothers revealed that NK cells are a major source of IFN $\gamma$ when exposed to P. falciparum antigens in vitro in the absence of any other co-stimulant. Future in vivo studies in populations affected with malaria should explore the significance of IL-2 on the production of IFN $\gamma$ at early stages of infection and in subjects with different degree of previous exposure to malarial antigens.

TNF is involved in the immune response to malaria as well as in the pathogenesis of severe disease[43,44]. Dysregulation and imbalance of this and other pro-inflamatory cytokines (TNF, IFN- $\gamma$, IL-12) versus antiinflammatory cytokines (IL-4, IL-6, transforming growth factor-1 beta, TGF-1 $\beta$ ) appear to be the main mechanisms resulting in the bias towards effective immune actions or tissue damage in the host [45]. The status of TNF in the context of NK cell activation was explored in the current study since these cells have been reported to be early producers of the cytokine after infection. The present results confirmed high levels of TNF-producing NK cells in acute and severe malaria patients, with $\mathrm{CD} 56^{\text {bright }}$ cells exhibiting the highest production of the cytokine in both infected groups.

\section{Conclusions}

The results confirm the important role of not only CD56 $6^{\text {bright }}$ but also of CD56 ${ }^{\text {dim }}$ NK cell populations as producers of the two cytokines in naturally infected malaria patients in Colombia. Future studies should include exploration of the status of activation of other 
lymphocyte populations and their relationship with NK cells in infected patients with malaria by $P$. vivax and $P$. falciparum exhibiting different clinical presentations.

\section{Acknowledgements}

We thank Dr Stephanie Yanow for comments on the manuscript and English proof-reading. This work was supported CODI, Estrategia Sostenibilidad 2011-2012, COLCIENCIAS code 1115-493-26134-contract 611/ 2009 and Grupo Salud y Comunidad, Universidad de Antioquia.

\section{Author details}

'Grupo Salud y Comunidad, Facultad de Medicina, Universidad de Antioquia, Medellin, Colombia. ${ }^{2}$ Grupo Reproducción, Facultad de Medicina, Universidad de Antioquia, Medellin, Colombia. ${ }^{3}$ Escuela de Microbiología, Universidad de Antioquia, Medellin, Colombia.

\section{Authors' contributions}

$\mathrm{OA}$ and $\mathrm{JB}$ designed and performed the NK analysis in blood samples. AV conceived the project and designed the experiments. AM designed the experiments, supervised overall design and development and wrote the manuscript. All authors read and approved the final manuscript.

\section{Competing interests}

The authors declare that they have no competing interests.

Received: 15 November 2011 Accepted: 8 February 2012

Published: 8 February 2012

\section{References}

1. Ross A, Smith T: Interpreting malaria age-prevalence and incidence curves: a simulation study of the effects of different types of heterogeneity. Malar J 2010, 9:132

2. Uscátegui RM, Correa AM, Carmona-Fonseca J: Cambios en las concentraciones de retinol, hemoglobina y ferritina en niños Colombianos con malaria. Biomedica 2009, 29:270-281.

3. Uscátegui RM, Correa AM: Nutritional status of children with malaria in northwest Colombia. Biomedica 2007, 27:559-570.

4. Subdirección de vigilancia y control en salud pública-Instituto Nacional de Salud: Malaria. Boletín Epidemiológico semanal 2009, 52:4-5.

5. WHO: World Malaria Report Geneva: World Health Organization; 2010, 238.

6. Instituto Nacional de Salud: Comportamiento de la malaria en colombia según los casos notificados al sivigila en 2009. Informe Epidemiológico Malaria 2010, 1-5.

7. Hafalla JC, Silvie O, Matuschewski K: Cell biology and immunology of malaria. Immunol Rev 2011, 240:297-316.

8. Walzer T, Dalod M, Robbins SH, Zitvogel L, Vivier E: Natural-killer cells and dendritic cells: "I'union fait la force". Blood 2005, 106:2252-2258.

9. Robbins SH, Bessou G, Cornillon A, Zucchini N, Rupp B, Ruzsics Z, Sacher T, Tomasello E, Vivier E, Koszinowski UH, Dalod M: Natural killer cells promote early CD8 T cell responses against cytomegalovirus. PLOS Pathog 2007, 3:e123.

10. Krebs P, Barnes MJ, Lampe K, Whitley K, Bahjat KS, Beutler B, Janssen E, Hoebe K: NK-cell-mediated killing of target cells triggers robust antigenspecific T-cell-mediated and humoral responses. Blood 2009, 113:6593-6602

11. Andrews DM, Estcourt MJ, Andoniou CE, Wikstrom ME, Khong A, Voigt V, Fleming P, Tabarias H, Hill GR, van der Most RG, Scalzo AA, Smyth MJ, Degli-Esposti MA: Innate immunity defines the capacity of antiviral T cells to limit persistent infection. J Exp Med 2010, 207:1333-1343.

12. Moretta A, Marcenaro E, Sivori S, Della Chiesa M, Vitale M, Moretta L: Early liaisons between cells of the innate immune system in inflamed peripheral tissues. Trends Immunol 2005, 26:668-675.

13. Vivier E, Raulet DH, Moretta A, Caligiuri MA, Zitvogel L, Lanier LL, Yokoyama WM, Ugolini S: Innate or adaptive immunity? The example of natural killer cells. Science 2011, 331:44-49.

14. Carson WE, Fehniger TA, Caligiuri MA: CD56bright natural killer cell subsets: characterization of distinct functional responses to interleukin-2 and the c-kit ligand. Eur J Immunol 1997, 27:354-360.
15. Gottschalk LR, Bray RA, Kaizer H, Gebel HM: Two populations of CD56 (Leu19)+/CD16+ cells in bone marrow transplant recipients. Bone Marrow Transplant 1990, 5:259-264.

16. Jacobs R, Hintzen G, Kemper A, Beul K, Kempf S, Behrens G, Sykora KW, Schmidt RE: CD56bright cells differ in their KIR repertoire and cytotoxic features from CD56dim NK cells. Eur J Immunol 2001, 31:3121-3127.

17. Engwerda C, Belnoue $E$, Grüner AC, Rénia L: Experimental models of cerebral malaria. Curr Top Microbiol Immunol 2005, 297:103-143.

18. Long GH, Chan BH, Allen JE, Read AF, Graham AL: Parasite genetic diversity does not influence TNF-mediated effects on the virulence of primary rodent malaria infections. Parasitology 2006, 133:673-684.

19. McCall MB, Roestenberg M, Ploemen I, Teirlinck A, Hopman J, de Mast Q, Dolo A, Doumbo OK, Luty A, van der Ven AJ, Hermsen CC, Sauerwein RW: Memory-like IFN- $\gamma$ response by NK cells following malaria infection reveals the crucial role of T cells in NK cell activation by P. falciparum. Eur I Immunol 2010, 40:3472-3477.

20. WHO: Guidelines for the treatment of malaria. Second edition. Geneve: World Health Organization; 2009, http://whalibdoc.who.int/publications/2010/ 9789241547925_eng.pdf accessed 27 October 2011.

21. López-Antuñano F: Diagnóstico microscópico de los parásitos de la malaria en la sangre. In Diagnóstico de malariaVolumen 512. Edited by: Lopez-Antuñano F, Schmunis G. Washington: OPS-OMS; 1988:39-50.

22. Urban $B C$, Ing R, Stevenson MM: Early interactions between blood-stage Plasmodiu parasites and the immune system. Curr Top Microbiol Immunol 2005, 297:25-70.

23. Combe $C L$, Curiel TJ, Moretto MM, Khan IA: NK cells help to induce CD8 (+)-T-cell immunity against Toxoplasma gondii in the absence of CD4(+) T cells. Infect Immun 2005, 73:4913-4921.

24. Liese J, Schleicher U, Bogdan C: The innate immune response against Leishmania parasites. Immunobiology 2008, 213:377-387.

25. Horowitz A, Riley EM: Activation of human NK cells by malaria-infected red blood cells. Methods Mol Biol 2010, 612:429-446.

26. Moretta L, Moretta A: Unravelling natural killer cell function: triggering and inhibitory human NK receptors. EMBO J 2004, 23:255-259.

27. Snyder MR, Weyand CM, Goronzy JJ: The double life of NK receptors: stimulation or co-stimulation? Trends Immunol 2004, 25:25-32.

28. Russell JH, Ley TJ: Lymphocyte-mediated cytotoxicity. Annu Rev Immunol 2002, 20:323-370.

29. Artavanis-Tsakonas K, Riley EM: Innate immune response to malaria: rapid induction of IFN-gamma from human NK cells by live Plasmodium falciparu-infected erythrocytes. J Immunol 2002, 169:2956-2963.

30. Artavanis-Tsakonas K, Eleme K, McQueen KL, Cheng NW, Parham P, Davis DM, Riley EM: Activation of a subset of human NK cells upon contact with Plasmodium falciparuminfected erythrocytes. J Immunol 2003, 171:5396-5405.

31. Hermsen CC, Konijnenberg Y, Mulder L, Loé C, van Deuren M, van der Meer JW, van Mierlo GJ, Eling WM, Hack CE, Sauerwein RW: Circulating concentrations of soluble granzyme $A$ and $B$ increase during natural and experimental Plasmodium falciparu infections. Clin Exp Immunol 2003, 132:467-472

32. Ribeiro-Dias F, Tosta CE: Dynamics and kinetics of natural killer cell cytotoxicity in human malaria as evaluated by a novel stepwise cytotoxicity assay. Rev Soc Bras Med Trop 2006, 39:357-364

33. Kassa D, Petros B, Mesele T, Hailu E, Wolday D: Characterization of peripheral blood lymphocyte subsets in patients with acute Plasmodium falciparu and P. viva malaria infections at Wonji Sugar Estate, Ethiopia. Clin Vaccine Immunol 2006, 13:376-379.

34. Dogruman-Al F, Fidan I, Kustimur S, Ceber K, Imir T: Determination of the expression of lymphocyte surface markers and cytokine levels in a mouse model of Plasmodium berghe. New Microbiol 2009, 32:285-291.

35. Lisse IM, Aaby P, Whittle H, Knudsen K: A community study of T lymphocyte subsets and malaria parasitaemia. Trans $R$ Soc Trop Med Hyg 1994, 88:709-710.

36. Lee HK, Lim J, Kim M, Lee S, Oh EJ, Lee J, Oh J, Kim Y, Han K, Lee EJ, et al: Immunological alterations associated with Plasmodium viva malaria in South Korea. Ann Trop Med Parasitol 2001, 95:31-39.

37. Hviid L, Kurtzhals JA, Goka BQ, Oliver-Commey JO, Nkrumah FK, Theander TG: Rapid reemergence of T cells into peripheral circulation following treatment of severe and uncomplicated Plasmodium falciparu malaria. Infect Immun 1997, 65:4090-4093. 
38. Korbel DS, Newman KC, Almeida CR, Davis DM, Riley EM: Heterogeneous human NK cell responses to Plasmodium falciparu-infected erythrocytes. J Immunol 2005, 175:7466-7473.

39. Mbugi EV, Meijerink M, Veenemans J, Jeurink PV, McCall M, Olomi RM, Shao JF, Chilongola JO, Verhoef H, Savelkoul HF: Effect of nutrient deficiencies on in vitro Th1 and Th2 cytokine response of peripheral blood mononuclear cells to Plasmodium falciparu infection. Malar J 2010, 9:162.

40. Newman KC, Korbel DS, Hafalla JC, Riley EM: Cross-talk with myeloid accessory cells regulates human natural killer cell interferon-gamma responses to malaria. PLoS Pathog 2006, 2:e118.

41. Korbel DS, Norman PJ, Newman KC, Horowitz A, Gendzekhadze K, Parham P, Riley EM: Killer Ig-like receptor (KIR) genotype predicts the capacity of human KIR-positive CD56dim NK cells to respond to pathogen-associated signals. J Immunol 2009, 182:6426-6434.

42. Horowitz A, Newman KC, Evans JH, Korbel DS, Davis DM, Riley EM: Crosstalk between T cells and NK cells generates rapid effector responses to Plasmodium falciparu-infected erythrocytes. J Immunol 2010, 184:6043-6052.

43. Marsh K, Snow RW: Host-parasite interaction and morbidity in malaria endemic areas. Philos Trans R Soc Lond B Biol Sci 1997, 352:1385-1394.

44. Rénia L, Potter SM, Mauduit M, Rosa DS, Kayibanda M, Deschemin JC, Snounou G, Grüner AC: Pathogenic T cells in cerebral malaria. Int J Parasitol 2006, 36:547-554.

45. Artavanis-Tsakonas K, Tongren JE, Riley EM: The war between the malaria parasite and the immune system: immunity, immunoregulation and immunopathology. Clin Exp Immunol 2003, 133:145-152.

doi:10.1186/1475-2875-11-38

Cite this article as: Agudelo et al:: High IFN-gamma and TNF production by peripheral NK cells of Colombian patients with different clinical presentation of Plasmodium falciparum. Malaria Journal 2012 11:38.

\section{Submit your next manuscript to BioMed Central} and take full advantage of:

- Convenient online submission

- Thorough peer review

- No space constraints or color figure charges

- Immediate publication on acceptance

- Inclusion in PubMed, CAS, Scopus and Google Scholar

- Research which is freely available for redistribution

Submit your manuscript at www.biomedcentral.com/submit
Biomed Central 